\title{
An Exploratory Study on The Use of 3d Hologram Visualization in Egypt's Educational Theater
}

\author{
Hisham Saad Zaghloul \\ Department of Self Development Skills, Deanship of Preparatory Year \& Supportive Studies, \\ Northern Border University, Saudi Arabia \\ Department of Educational Media, Faculty of Specific Education, Mansoura University, Egypt
}

Received: April 14, 2020. Revised: June 5, 2020. 2nd Revised: June 19, 2020. Accepted: June 22, 2020. Published: June 22, 2020.

\begin{abstract}
This research paper is an exploratory study on the uses of hologram technology in educational theaters in Egyptian schools. Considering theater as one of the instructional methods adopted by the Egyptian Ministry of Education in the school curricula, and as an accredited school activity within a group of other educational activities. The introduction provides an overview of holographic technology and predicts its future in student learning. It further outlines educational activities that have become heavily dependent on technology in training and application, with the simplistic definition of 3D technology and 3D imaging explained. The literature review presents publications in hologram technology and related publications, explaining the different concepts of holographic, virtual, and augmented reality. The applicability of these concepts is elucidated, especially in theater activity as an educational tool in schools and educational institutions. Besides, the research focuses on the educational theater in Egypt, and the use of technology as a supportive means of achieving the goals of educational activities that may apply to exceptional capabilities and requirements. Modern technology using hologram may provide solutions to basic requirements for the stage, lighting arts, decoration, and theatrical illusions to achieve the goals of theatrical performances for educational purposes. The study used a sample size of $\mathbf{4 0 0}$ individuals represented as those responsible for performing theater activity in several schools in four different governorates in Egypt. The study results showed the impact of holographic technology in Egyptian school theaters and future challenges that may hinder the implementation of holographic technology in educational theatres, making references to previous studies on the topic. In its
\end{abstract}

conclusions, the study addressed the funding gap and other challenges facing the implementation of hologram technology in educational theaters in Egypt.

Keywords-hologram, 3D holographic visualization technology, educational theater.

\section{INTRODUCTION}

$\mathrm{M}$ odern 3D visualization methods are applicable in several sectors, including the entertainment industry, medicine, and education sectors [1]. In the past decade, a non-holographic computer was leading in the tech world. Research into the use of 3D holographic visualization has profoundly mushroomed. Currently, educational theaters have introduced 3D holographic technology in learning. Further, researchers have a positive projection on the future merits of 3D visualization technology. Akin to note is the fact that $3 \mathrm{D}$ visualization has a set of challenges that are solved by holograms [2]. One such problem is the accommodation of the observer's eye. These challenges can be offset through technological advancement and meticulous research on the use of 3D holographic technology in educational theaters.

The efficacy of novel technology is dependent on both the technology itself and the end-user. Holographic technology use and implementation in educational theaters might prove challenging for individuals without a deep understanding of its functionality [3]. The more reason students should get educated on its use before the implementation of the technology. The merits pegged on the technology, including student learning and cognition, validate it for application in academic institutions. The most critical factor to consider while implementing the technology is the aspect of the cost and its effects on the students. Besides, 3D holographic technology has not advanced to the sophisticated level that it should; therefore, researchers and academic institutions are on standby, waiting for the technology to develop and augment artificial intelligence within its operation framework [3].

In educational theaters installing 3D holograph, visualization is critical in ensuring students are comfortable, 
and optimum results are derived classroom learning. Theater in education aims at encouraging effective learning in schools. In designing educational theaters for which 3D holographic visualization technology is to be installed, careful consideration of the age of the students ought to be made to engage them more effectively [4]. The theater has a high impact on performance for a huge student audience. In the past, theater in education projects was funded centrally in Egypt. Currently, companies seek funding for schools to provide services according to the specifications of the schools.

There are four primary factors to consider in the design of educational theaters. These factors include convenience, noise, light, and theater size. The educational theater should have a convenient location for easy accessibility by the students. Further, educational theaters are renowned for generating lots of noise. Therefore, soundproofing is vital in keeping the noise within the theater. The educational theaters should be ejected far from institutional hospitals and boardrooms to avoid noise interference. One of the distinguishing characteristics of educational theaters is the operators' ability to control the lighting. Too much light in the theaters is considered an inconvenience because light might interrupt the clear viewing of screens [5]. Finally, the theater should be large enough to accommodate the huge student audience without interfering with the sound system or lighting.

Decoration and theatrical sonography are equally important aspects to consider in designing educational theaters. Researchers have identified that decorating educational theaters sets the tone of learning. Students derive a sense of pride and ownership through decorations hence developing a sense of community in the educational theaters. Therefore, educational theater décor is a vital teaching tool. The decorations must be creative with due considerations made to the audience (children). Sonography in theater design focuses on sound quality and reception by the audience, which is a primary concern for the designers [6].

The interest of this paper is the application of holographic images in education in Egypt's educational theaters for the learning of children. The current transforming world and artificial intelligence, present unexploited possibilities in the tech world [7]. The scientific predictions of scholars and researchers regarding the future of holograms is promising. However, investment in terms of research and equipment requirements is costly. There ought to be a collaborative effort in implementing holographic imaging technology in learning through educating students on the functionality of holograms and the merits it brings to education [7]. Ultimately, holograms should be included early in the syllabus to facilitate expedited understanding of the application of this technology before students begin to use it. This paper critically analyzes the use of hologram technology in Egyptian educational centers.

\section{Problem Statement}

The 3D holographic visualization technology is a novel technology whose application in the educational theaters in Egypt has not been affected. There is a need to identify the impact of 3D holographic visualization on student learning and how to implement the technology in educational theaters to achieve children's progressive learning outcomes. This research paper aims at identifying the research loopholes in the implementation of 3D holographic visualization in Egyptian educational theaters and the challenges the technology potentially faces in its implementation.

\section{Research Questions}

This research paper seeks to answer the following research questions:

1. What is the impact of implementing 3D holographic visualization in Egyptian educational theaters on student learning?

2. What are the challenges facing the implementation of the $3 \mathrm{D}$ holographic visualization in Egypt's learning institutions?

\section{LITERATURE REVIEW}

\section{A. Historical Context of the 3D Holographic Visualization}

The new 3D holograms came about with the invention of laser technology. A laser creates pure light waves that are coherent. Coherent light waves facilitate the recording of light wave interference patterns of holography. In 1917, Sir Albert Einstein hypothesized stimulated emission, which is a process making lasers possible [8]. Afterward, physicists like Arthur Schawlow and Charles Townes published the idea of the laser in 1958. NJ constructed the first operational ruby laser. Theodore Maimane in 1960 in California. In 1963, the magnificent invention of the semiconductor injection laser by Robert Hall followed [9]. Gordon Gould was the trailblazer in coining the word LASER (Light Amplification by Stimulated Emission of Radiation) in 1977, having been awarded the basic patent for laser by the US Patent Office [8].

However, holography was a precursor to the laser. In 1886, a scientist Gabriel Lippmann came up with a theory of light wave interference to capture color in photography (Hill Jr et al., 2003). The theory utilized mercury on the backside of photographic plates bouncing back light waves through the process of emulsion, thus facilitating interference. Gabriel's theory was presented to the Academy of Sciences in 1891, after which the presentation of perfect color photograph followed in 1893 [10]. Lippmann published his entire story in 1894. The wave interference color photographs invented and published by Lippmann were the predecessor to holograms. Dennis Gabor, through his theory of wavefront reconstruction, came up with the name holography. In 1971, Gabor won the Nobel Prize in Physics for this holography theory [11].

Yuri Denisyuk, having read Lippmann's explanation of interference photography, noticed the technology could be utilized in the recording of 3D images. Denisyuk instigated experiments in 1958 using a highly filtered mercury expulsion tube as the source of light [1]. The laser technology was nonexistent at the time. Denisyuk came up with the first 3D reflection holograms. Emmett Leith, having never read or heard of Gabor's work, reinvented holography in 1958. Emmett and Juris Upatkniks, with the invention of the helium-neon laser, introduced their work to the world on 3D laser transmission holography in 1961 completely oblivious of Densyuk's work [11]. 
3D holography technology is currently used in the film industry, with the audience getting entertained with 3D movies. Smartphone-based augmented reality in the future intends to include 3D holograms into every aspect of human life. The hologram technology has become increasingly ubiquitous, with tech companies striving to dominate the market. HoloLens, popularly known as the light ware, has been in the news after a 6-year development costing over $\$ 2$ billion. Computers and smartphone screens show an artificial 2D version of the world [12]. A hologram can transform our perception of the world and how children's learning comprehension. Scientists project that holograms will improve training, visualization, and design in enterprises.

\section{B. Visualization In $3 d$ Computer Graphics}

Holograms offer profound advantages in the current tech world and science in general. One such merit is spatial visualization. The term refers to the ability to manipulate objects in imaginary 3D space and represent the object in a new point of view [13], [14]. 3D visualization of objects is not a new concept in the context of computer graphics. However, the multidisciplinary evolution of 3D spatial visualization is a significant focus of scientists [15]. Image depth perception developed from monocular depth cues in 3D computer graphics, for example, in texture gradients and aerial perspective creates an illusion of depth in images' flat surfaces. According to research, 84 fields of specialty require developed rotation abilities and spatial visualization and have a vast contribution to engineering [15], [13].

\section{Holograms and Virtual versus Augmented Reality}

There is a protruding distinction between holograms, virtual reality (VR), and augmented reality (AR). Scholars and IT specialists have always found it confusing in the initial stages of studying the subject. AR and VR share computer-generated visual scenes and a wide variety of interactive components [16]. The primary difference between these two technologies (VR and AR) lies in their use. Augmented reality supplements the world, while virtual reality tends to substitute the real world with virtual objects completely. Subtly put, virtual reality represents a computer developed world [16].

In contrast, holography neither involves VR nor IR. In principle, holography represents manipulated objects to achieve the desired outcome. Therefore, it is possible to view an image long after the withdrawal of the object through holography [16].

Although holography, VR, and IR use the same technology, these technologies operate on entirely different concepts [15]. In holography, light is encrypted into a chip after taking light around an object. Holograms capture light's phase giving it a $3 \mathrm{D}$ appearance. In essence, the hologram is composed of two terms: holes and gram. The former means complete view while the latter stands for written. According to Sudeep [17], a hologram is a 3D record of the interfering of light waver of lasers. 3D visualizations in holography can profoundly add value to the pre-existential fields of medical imaging devices and geological exploration.
The advancement of holograms facilitates the multidisciplinary application of technology. Interestingly, holograms augment current technologies [15]. For example, holograms are attached to chips of credit cards, currency notes, and biomedical equipment. Holography is a technology that cannot be ignored. During the 1980s, static analog holograms were popular. Technology has not advanced into 3D dynamic holographic technology [15]. Science has proven that the brain of a person may grasp memories in a holographic fashion according to the Holographic Brain theory suggested by Pribram [15]. According to the method, holographic data is localized, for instance, in explicit pictures. Further, each part of the human memory contains critical information regarding the data in its entirety [15]. Living systems require both intellectual ability and associative ability with which the brain comprehends the links between information units not involved in learning or cognitive processes.

\section{Holographic Technology in Educational Theaters}

2D media is convenient, inexpensive, and flexible, thus profoundly used in educational settings. The downside of $2 \mathrm{D}$ static representation is the fact that the natural world, which is $3 \mathrm{D}$ in reality, is not reflected [18]. The modern virtual 3D environment is appropriate for the learning of students because the students are attached to a virtual world similar in some ways to their real world. According to Kesim and Ozarslan [19], virtual 3D environments represent augmented reality allowing users to view the real world to supplement reality devoid of completely submerging users into a synthetic environment.

The development and implementation of holographic technology are performed outside the confines of academics, the academic potential of holographic technology could substantially enhance the experiences of the learners, and their tutors [20]. Academic paradigms have shifted from teachercentric to student-centered learning models; consideration of knowledge transfer mechanisms is vital in adjusting to such model changes. The first 3D holograms were created in the 1960s, following which the 2008 presentation of Bill Gates at the World Congress of Information and Technology occurred [21]. The presentation was exhibited as a holographic image in Malaysia. Holographic image presentations have become a common phenomenon in the 21 st century [22].

Some challenges may hinder the implementation of $3 \mathrm{D}$ holographic technology within a student's learning environments. 3D renderings quality dictates instructional effectiveness in several disciplines. For example, in the field of medicine, BioDigital Human is a medical visualization program that facilitates understanding of physiology and anatomy [23]. Holographic renderings and computer renderings have distinguishable characteristics. For instance, holographic renderings resemble cartoons, while $3 \mathrm{D}$ printed models are equally different from the duo [23].

Further, viewing 3D images causes visual fatigue. Cyber sickness is a common term used for virtual reality induced illness in many research studies [24]. The student's learning outcomes must be geared towards enhancing teacher-student interactions and fine-tuning the student-centered approach to learning to achieve effective results [25]. Egypt's learning system embraces a somewhat progressive educational system 
delving from the antiquated teacher-centered learning and specifically focused on student understanding and enhanced learning experience. the visual fatigue problems introduced by $3 \mathrm{D}$ visualization technology can be offset by introducing breaks in the process of learning.

The primary concern of implementing $3 \mathrm{D}$ hologram imaging and videos in the learning of students is the aspect of the cost [26]. Though learning effectiveness is guaranteed through implementing the technology in learning facilities, the process is expensive, and the tools needed are equally costly. At this immature stage of hologram technology, several educational establishments may be unsure if investing in technology is worth the risk [24]. Therefore, conducting a cost-benefit analysis is the best strategy to employ while deciding on whether to implement holographic technology in academic institutions [21].

\section{METHODOLOGY}

Analyzing the efficacy of implementing 3D hologram imaging technology in education is possible through conducting a comprehensive survey. For this study, Cairo was the best place for implementing the technology because of the city's strategic location and the concentration of most of Egypt's professionals at this location. Teachers in Egypt were questioned about their perception and knowledge regarding 3D holographic visualization. The method of data collection employed was questionnaires and direct personal interviews. The teachers had to be conversant with 3D imaging and its projected application in education.

Participation in the survey was voluntary, and any participant was at liberty to withdraw from the process at any particular stage. A mixed-methods approach to research was used to reach more respondents conveniently. Further, the method facilitated data accuracy. A quasi-experimental study done fostered investigation of a comparative analysis of the impact of including 3D holographic images in children's theaters in Egypt. The selected respondents were from all levels of education. In the process of collecting data, the researcher had to assess the knowledge of the respondents regarding holographic technology.

\section{Ethical Considerations in Data Collection}

The researcher had to follow informed-consent rules. The consent process sensitized the respondents on the risks and benefits of voluntarily participating in the survey. All information influencing the respondents' willingness to participate in the study was given in a form they understood. Communication had to be clear and transparent without manipulation. The goal of this survey was to explore the implementation of holography in educational theaters in Egypt. The respondents were made aware of the risks associated with the study and the desired outcome (s).

Individuals' right to privacy and confidentiality were upheld as sacrosanct. The researcher devised an indirect method of asking whether the participants were willing to talk about sensitive topics without making them uncomfortable. A series of detailed interview structured questions and a clause permitting the respondents to answer the questions ensured confidentiality and privacy in the survey. Participants were free to reveal the extent of personal information they were willing to share. All the respondents selected for this survey knew 3D holographic visualization and its implementation in the educational theaters.

The survey addressed issues with the limits of confidentiality. The respondents were informed about how their data was used, case materials, audio, video recordings, and the researcher obtained the participants' consent. Licenses and permits required for the survey were obtained before the survey. In a bid to maximizing information accuracy and the overall effectiveness of the data collection, the researcher explained the meaning and use of 3D holographic technology. Further, before filling out the questionnaires, the researcher explicitly clarified each question to steer clear of any ambiguous interpretation.

Follow-ups were carried out with the respective participants and questionnaires collected once the survey was complete. Questionnaire questions were evaluated by a pilot study and tested before dissemination. A sample questionnaire for this survey is presented in Appendix A. A pilot study and followups were essential steps in evaluating the respondents' interpretation of the questions [27]. Questionnaires are the most effective method of data collection within a short time. Data analysis through simulations and software, such as SPSS, are also valid [28].

\section{STATISTICAL TREATMENT AND RESULTS}

This Survey conducted in Egyptian learning institutions in 2011. Questionnaires were sent to 400 respondents randomly chosen with different levels of education in four Egyptian governorates. (Dakahlia - Menoufia Cairo - Gharbia) The research aimed to ascertain whether learning in schools will be significantly enhanced by implementing 3D holographic technology in educational theaters. All the participants were involved in the study. Table 1.0 below shows the response.

Table 1. Questionnaire response data

\begin{tabular}{|l|c|c|c|}
\hline \multicolumn{4}{|c|}{ Response data } \\
\hline Participants & Research tool & Sample & $\begin{array}{c}\text { Percentage } \\
\text { response }\end{array}$ \\
\hline $\begin{array}{l}\text { Teachers } \\
\text { (School theater } \\
\text { specialists) }\end{array}$ & Questionnaire & 400 & $100 \%$ \\
\hline
\end{tabular}

The researcher was interested in identifying the relationship between teachers' level of education and their perception of whether the implementation of 3D holographic visualization in educational theaters will enhance learning. $228(57 \%)$ of the respondents affirmed that 3D holographic technology in educational theaters could have a tremendous effect on student learning, while $59(14.7 \%)$ of the sampled population declined. The rest $113(28.3 \%)$ did not know the repercussions of 3D holographic visualization in educational theaters on the learning of students in Egyptian schools.

The respondent's response data clarified that a significant number of respondents trust that 3D holographic visualization in educational theaters will support the process of learning. The data also revealed that the teachers responsible for teaching the school theater in a higher level of education have a greater 
belief in the positive impact of 3D holographic visualization in educational theaters on student learning in Egypt. 44 primary teachers responded Yes, 4 said No while 52 responded I don't Know. The primary school teachers represent the highest percentage of teachers who are unsure of the learning potential of $3 \mathrm{D}$ holographic visualization in educational theaters. This was contrary to the responses given by higher education teachers; 79 teachers affirmed the importance of 3D hologram visualization in educational theaters in enhancing learning. Table 2 below shows the responses with regards to the relationship between 3D hologram visualization in educational theaters and learning enhancement.

Table 2. Response to learning enhancement

\begin{tabular}{|l|c|c|c|c|c|}
\hline $\begin{array}{l}\text { Does 3D holographic } \\
\text { Visualization in educational } \\
\text { theaters enhance learning? }\end{array}$ & Primary & $\begin{array}{c}\text { Lower } \\
\text { Secondary }\end{array}$ & Upper Secondary & Higher Education & TOTAL \\
\hline$\square$ Yes & 44 & 55 & 50 & 79 & 228 \\
$\square$ No & 4 & 20 & 30 & 5 & 59 \\
$\square$ I don't know & 52 & 25 & 20 & 16 & 113 \\
\hline TOTAL & 100 & 100 & 100 & 100 & 400 \\
\hline
\end{tabular}

Table 3. below shows the response data for other questions in the questionnaire attached to the appendix section of this research paper.

Table 3. Questionnaire responses: 3D Holographic Technology in Egypt's Educational Theatre

\begin{tabular}{|l|l|c|}
\hline \multicolumn{1}{|c|}{ QUESTION } & \multicolumn{1}{|c|}{ Response } & TOTAL \\
\hline & $\square$ Yes & 400 \\
Do you know what 3D holographic technology in educational theaters is? & $\square$ No & 0 \\
\hline Do you think the 3D holographic technology will be a tool for a teacher in & $\square$ Yes & 233 \\
educational theaters? & $\square$ No & 42 \\
& $\square$ I don't know & 125 \\
\hline $\begin{array}{l}\text { Do you think the 3D holographic technology will be a tool for a teacher in } \\
\text { educational theaters? }\end{array}$ & $\square$ Yes & 250 \\
& $\square$ No & 21 \\
\hline
\end{tabular}
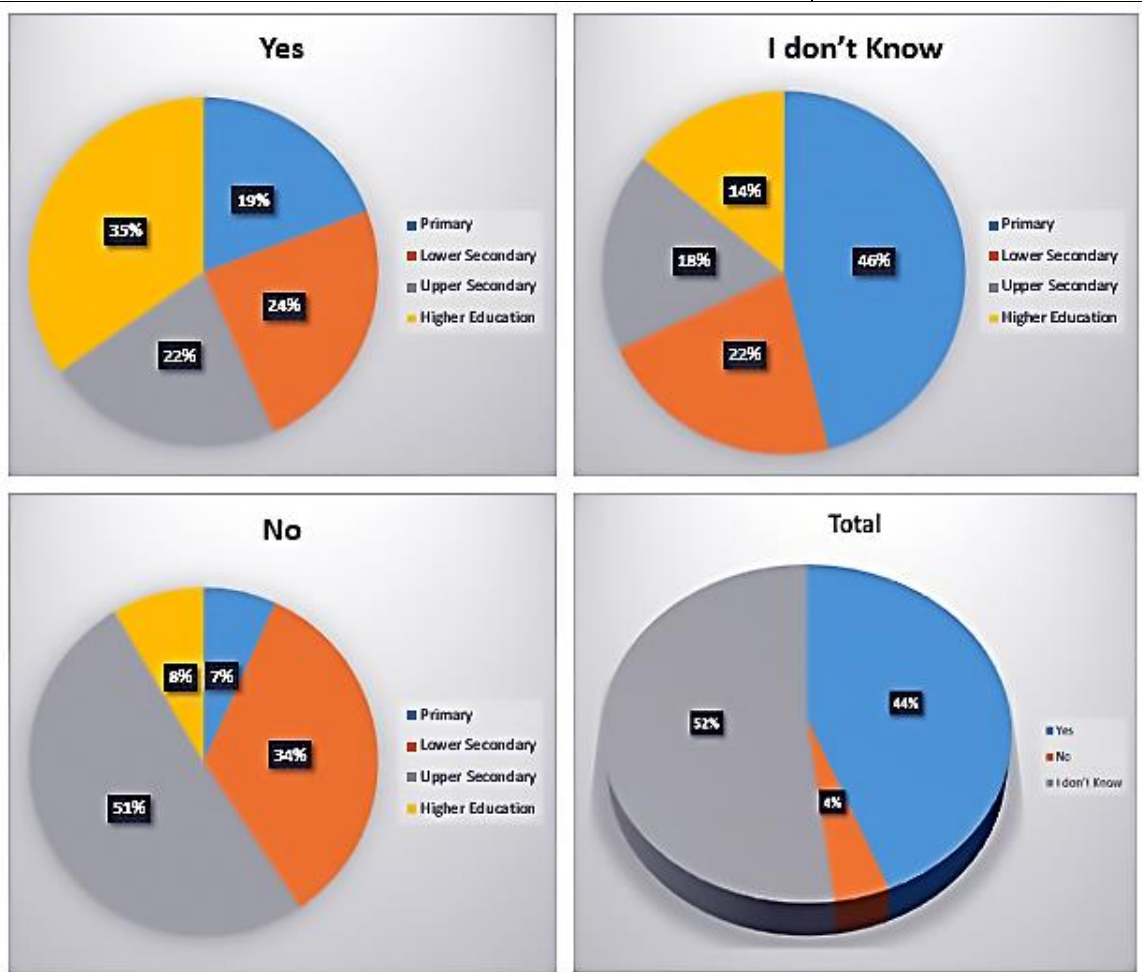

Figure 1: Pie Chart representation of teacher's responses at all levels of education on the learning enhancement of 3D holographic visualization in Egypt's educational theater 
The number that chose the "I don't know" option was significant. This fact shows that a representative number of educators lack knowledge on the potential of the 3D hologram visualization in educational theater. It is also possible that the teachers have insufficient knowledge of the technology in educational theaters. The impact of technology on the learning of children is common knowledge, failing to project the possibilities there are in the use of 3D hologram visualization in educational theater emphasizes the need to train teachers and students before launching the technology in educational theaters. Besides, the research revealed that teachers at higher levels of education (university and high school) were in support of implementing 3D holographic technology in educational theaters. These teachers perceived 3D holographic technology in educational theaters as an essential technology in supporting the education process. Averagely, the respondents rated the efficacy of $3 \mathrm{D}$ hologram visualization in educational theater in learning at 7.7. Therefore, a majority of the respondents believe that $3 \mathrm{D}$ hologram visualization in the educational theater will be effective in learning in the future and at present.

\section{T-test Results}

The t-test values revealed significant results. In the test, the yes and no values of the participants in the research were treated as two independent variables. The data has been rounded off to two significant figures apart from the $t$ and $p$ values. Calculating these values based on the summary data provided provides a different and less accurate result. Such is the case while dealing with numbers that are fractions of 1 as is the case. The results are as below.

Table 4. Independent variable: Yes

\begin{tabular}{|c|c|c|}
\hline Treatment 1 $(\mathrm{X})$ & Diff $(\mathrm{X}-\mathrm{M})$ & Sq. Diff $(\mathrm{X}-\mathrm{M})^{2}$ \\
\hline 44 & -13.00 & 169.00 \\
\hline 55 & -2.00 & 4.00 \\
\hline 50 & -7.00 & 49.00 \\
\hline 79 & 22.00 & 484.00 \\
\hline & M: 57.00 & SS: 706.00 \\
\hline
\end{tabular}

Table 5. Independent Variable: No

\begin{tabular}{|c|c|c|}
\hline Treatment 1 $(\mathrm{X})$ & Diff $(\mathrm{X}-\mathrm{M})$ & Sq. Diff $(\mathrm{X}-\mathrm{M})^{2}$ \\
\hline 4 & -10.75 & 115.56 \\
\hline 20 & 5.25 & 27.56 \\
\hline 30 & 15.25 & 232.56 \\
\hline 5 & 9.75 & 95.06 \\
\hline & $\mathrm{M}: 14.75$ & SS: 470.75 \\
\hline
\end{tabular}

Table 4 and Table 5 above show the Yes and No independent variables which are primary inputs for computing the $t$-value $\mathrm{p}<$ .05 .

It is important to note that the $M$ values are the median value while the $X$ values are the values of the independent variable. Significance level: 0.05 One-tailed hypothesis.

\section{Difference Scores Calculations}

\section{Treatment 1}

$N_{1}: 4$

$d f_{1}=N-1=4-1=3$

$M_{1}: 57$

$S S_{1}: 706$ $s^{2}{ }_{1}=S S_{1} /(N-1)=706 /(4-1)=235.33$

Treatment 2

$N_{2}: 4$

$d f_{2}=N-1=4-1=3$

$M_{2}: 14.75$

$S S_{2}: 470.75$

$s_{2}^{2}=S S_{2} /(N-1)=470.75 /(4-1)=156.92$

T-value Calculation

$s_{p}^{2}=\left(\left(d f_{1} /\left(d f_{1}+d f_{2}\right)\right) * s^{2}\right)+\left(\left(d f_{2} /\left(d f_{2}+d f_{2}\right)\right) * s_{2}{ }_{2}\right)=((3 / 6) *$

$235.33)+((3 / 6) * 156.92)=196.12$

$s^{2}{ }_{M 1}=s^{2}{ }_{p} / N_{1}=196.12 / 4=49.03$

$s^{2}{ }_{M 2}=s_{p}^{2} / N_{2}=196.12 / 4=49.03$

$t=\left(M_{1}-M_{2}\right) / \sqrt{ }\left(s_{M 1}^{2}+s^{2}{ }_{M 2}\right)=42.25 / \sqrt{ } 98.06=4.27$

The $t$-value is 4.26653 . The $p$-value is .002642 . The result is significant at $p<.05$.

Case 2: Treating Yes and I don't know values as independent variables.

Table 6. Independent variable: Yes

\begin{tabular}{|c|c|c|}
\hline Treatment 1 $(\mathrm{X})$ & Diff $(\mathrm{X}-\mathrm{M})$ & Sq. Diff $(\mathrm{X}-\mathrm{M})^{2}$ \\
\hline 52 & 23.75 & 564.06 \\
\hline 25 & -3.25 & 10.56 \\
\hline 20 & -8.25 & 68.06 \\
\hline 16 & 12.25 & 150.06 \\
\hline & M: 28.25 & SS: 792.75 \\
\hline
\end{tabular}

Table 7. Independent Variable: I don't know

\begin{tabular}{|c|c|c|}
\hline Treatment 1 $(\mathrm{X})$ & Diff $(\mathrm{X}-\mathrm{M})$ & Sq. Diff $(\mathrm{X}-\mathrm{M})^{2}$ \\
\hline 44 & -13.00 & 169.00 \\
\hline 55 & -2.00 & 4.00 \\
\hline 50 & -7.00 & 49.00 \\
\hline 79 & 22.00 & 484.00 \\
\hline & M: 57.00 & SS: 706.00 \\
\hline
\end{tabular}

Table 6 and Table 7 above show Yes, and I don't know independent variables used to calculate the t value $p<.05$. Difference Scores Calculations

\section{Treatment 1}

$N_{1}: 4$

$d f_{1}=N-1=4-1=3$

$M_{1}: 57$

$S S_{1}: 706$

$s^{2}{ }_{1}=S S_{1} /(N-1)=706 /(4-1)=235.33$

\section{Treatment 2}

$N_{2}: 4$

$d f_{2}=N-1=4-1=3$

$M_{2}: 28.25$

$S S_{2}: 792.75$

$s_{2}^{2}=S S_{2} /(N-1)=792.75 /(4-1)=264.25$

T-value Calculation

$s_{p}^{2}=\left(\left(d f_{1} /\left(d f_{1}+d f_{2}\right)\right) * s^{2}\right)+\left(\left(d f_{2} /\left(d f_{2}+d f_{2}\right)\right) * s_{2}{ }_{2}\right)=((3 / 6) *$

$235.33)+((3 / 6) * 264.25)=249.79$

$s^{2}{ }_{M 1}=s_{p}^{2} / N_{1}=249.79 / 4=62.45$

$s^{2}{ }_{M 2}=s^{2}{ }_{p} / N_{2}=249.79 / 4=62.45$

$t=\left(M_{1}-M_{2}\right) / \sqrt{ }\left(s^{2}{ }_{M 1}+s^{2}{ }_{M 2}\right)=28.75 / \sqrt{ } 124.9=2.57$

The $t$-value is 2.57255 . The $p$-value is .021095 . The result is significant at $p<.05$. 
Case 3: Treating No and I don't know values as independent variables.

Table 8. Independent variable: No

\begin{tabular}{|c|c|c|}
\hline Treatment 1 $(\mathrm{X})$ & Diff $(\mathrm{X}-\mathrm{M})$ & Sq. Diff $(\mathrm{X}-\mathrm{M})^{2}$ \\
\hline 4 & -10.75 & 115.56 \\
\hline 20 & 5.25 & 27.56 \\
\hline 30 & 15.25 & 232.56 \\
\hline 5 & -9.75 & 95.06 \\
\hline & M: 14.75 & SS: 470.75 \\
\hline
\end{tabular}

Table 9. Independent variable: I don't know

\begin{tabular}{|c|c|c|}
\hline Treatment $1(\mathrm{X})$ & Diff $(\mathrm{X}-\mathrm{M})$ & Sq. Diff $(\mathrm{X}-\mathrm{M})^{2}$ \\
\hline 52 & 23.75 & 564.06 \\
\hline 25 & -3.25 & 10.56 \\
\hline 20 & -8.25 & 68.06 \\
\hline 16 & -12.25 & 150.06 \\
\hline & M: 28.25 & SS: 792.75 \\
\hline
\end{tabular}

Table 8 and Table 9 show the No and I don't know independent variables used to calculate the $\mathrm{t}$-value at $\mathrm{p}<.05$.

Difference Scores Calculations

\section{Treatment 1}

$N_{1}: 4$

$d f_{1}=N-1=4-1=3$

$M_{1}: 14.75$

$S S_{1}: 470.75$

$s^{2}{ }_{1}=S S_{1} /(N-1)=470.75 /(4-1)=156.92$

Treatment 2

$N_{2}: 4$

$d f_{2}=N-1=4-1=3$

$M_{2}: 28.25$

Table 10. Results for the chi-square tests

\begin{tabular}{|c|c|c|c|c|c|}
\hline & Primary & Lower Secondary & Upper Secondary & Higher Education & Row Totals \\
\hline Yes & $44(57.00)[2.96]$ & $55(57.00)[0.07]$ & $50(57.00)[0.86]$ & $79(57.00)[8.49]$ & 228 \\
\hline No & $4(14.75)[7.83]$ & $20(14.75)[1.87]$ & $30(14.75)[15.77]$ & $5(14.75)[6.44]$ & 59 \\
\hline I don't Know & $52(28.25)[19.97]$ & $25(28.25)[0.37]$ & $20(28.25)[2.41]$ & $16(28.25)[5.31]$ & 113 \\
\hline Column Totals & 100 & 100 & 100 & 100 & 400 \\
\hline
\end{tabular}

Table 10 shows the results for the chi-square tests at $\mathrm{p}<.05$ The chi-square statistic is 72.3632 . The $\mathrm{p}$-value is $<0.00001$.

The result is significant at $\mathrm{p}<.05$.

Table 11. Contingency table

\begin{tabular}{|l|c|c|c|c|c|}
\hline Category & Observed & expected & residual & (Obs-expected)2 & (Obs-exp)2/exp \\
\hline Primary, yes & 44 & 57 & -13 & 169 & 2.96 \\
\hline Primary; no & 4 & 14.75 & -10.75 & 115.56 & 7.83 \\
\hline Lower sec; yes & 55 & 57 & -2 & 4 & 0.07 \\
\hline Lower sec; no & 20 & 14.75 & 5.25 & 27.56 & 1.87 \\
\hline Upper sec; yes & 50 & 57 & -7 & 49 & 0.86 \\
\hline Upper sec; no & 30 & 14.75 & 15.25 & 232.56 & 8.78 \\
\hline Higher ed; yes & 79 & 57 & -22 & 484 & 6.44 \\
\hline Higher ed; no & 5 & 14.75 & 9.75 & 95.06 & 44.3 \\
\hline
\end{tabular}


Ho: there is no relationship between the level of education to the understanding of the concept, they are independent.

H1: $_{1}$ there is a relationship between the level of education and understanding the concept of 3D holographic technology; they are dependent.

C. $195 \%=0.05$

$\mathrm{X}^{2}=\sum(\mathrm{O}-\mathrm{E})^{2} / \mathrm{E}=44.3$

Df $=(\mathrm{r}-1)(\mathrm{c}-1)(8-1)(6-1)=35$

Critical value (from t-tables, at a confidence level of 95\%)

$=1.69$

It, therefore, implies that understanding of the 3D holographic technology is dependent on the level of education of the respondents.

\section{Explanation}

The Chi-square test and t-test reveal that the data is profoundly significant. However, for the t-test, the test for No against I don't know responses are trivial hence insignificant at $\mathrm{p}<.05$. The significant results manifest in the t-test and chisquare attest to the validity of the research method used. This research is unique, given there have not been prior studies explicitly testing the use of 3D holographic technology in educational theaters in Egypt. However, projections of the results concerning the future of $3 \mathrm{D}$ technology in other disciplines are consistent with other research findings. The two negative responses "I Don't Know" and "No", albeit treated as independent variables are infinitesimally correlated. Therefore, the results of the t-test are highly valid further bolstered by the chi-square calculations.

Generally, a majority of the teachers supported the implementation of the 3D holography imaging technology in educational theaters. Moreover, the respondents were in favor of using hologram technology as a tool for the teachers in educational theaters. Nevertheless, they identified the high costs of installation as one of the difficulties facing the integration of technology to learning in educational theaters. Most of the interviewees confirmed that 3D hologram visualization technology is a possible future teaching tool. However, most of the selected respondents were of the perception that the 3D holographic visualization technology has a limited effect on the face of education. A fast internet connection and high installation costs are some of the identified challenges by the respondents as far as the integration of the technology into the educational curriculum are concerned.

\section{DISCUSSION}

Studies indicate that holographic displays affect spatial visualization. Further, holographic imaging has a progressive impact on the learning and cognitive development of children [1]. Holographic projections in engineering data and medical images are a recent visualization topic [29]. The optical specification is required for complex visualizations. However, it is a costly procedure. There has been an increased demand for mature 3D displays with the advancement in technology and other hologram visualizations. Accurate predictions, through research, presupposed that $3 \mathrm{D}$ presence construction would be possible by the year 2018, which was realized recently. There have been extensive uses of 3D holographic technology in military training, the entertainment industry, and medicine [29].

Though holographic technology is used outside the education field, the technology has potential in academia. Students have the potential to use their acquired experiences to construct knowledge. The input of 3D hologram in engineering and technology, specifically in coursework like engineering graphics and manipulation of large data sets, can be very instrumental in streamlining learning and the curriculum [1]. The learning environment can be quite rewarding through augmented and virtual reality. The efficacy of 3D holographic technology has been on research for decades. However, there has not been a breakthrough in accurately pinpointing and implementing the effectiveness of hologram technology in academia [30]. All the merits currently identified are mere projections and not realities.

Hologram imaging technology is one of the modern techniques based on 3D imaging. Research has projected that 3D holographic imaging technology will exceed the confines of science and technology and profoundly benefit the education sector. 3D holographic imaging can create interactive virtual environments that facilitate the achievement of objectives in education [31]. In this research, the success of implementing 3D holographic technology in Egyptian schools is discussed in depth. Implementation of this technology facilitates goal attainment linked to the educational curricula [31]. The discussion section accomplishes three primary objectives of this study, including establishing the history of holographic technology, assessing the readiness of Egyptian schools in implementing 3D holographic imaging within its educational curriculum, developing the learning outcome(s) of students as a consequence of applying the 3D holographic visualization [31].

\section{The Importance of 3D Holography in Learning}

A 2009 research conducted on a sampled teacher population in the United Kingdom revealed that $45.5 \%$ of the respondents established the significance of 3D Hologram Technology on the future learning of students in educational theaters [16]. However, $47.3 \%$ of the respondents confirmed that the implementation of the technology in educational theaters will not profoundly affect education and will, therefore, have an insignificant [16]. These claims assert how little is known about 3D holographic technology and the potential the technology has in learning institutions. However, the respondents indicated that the high cost of installation and high-speed internet connection are the potential limits to the implementation of the technology [16].

In traditional classroom learning, the teacher is the sole instruction giver, and the students are the passive receivers of the instruction [32]. The rapid developments in technology have tremendously transformed many spheres of influence. Educational institutions have been at the forefront of integrating Information Communication Technology (ICT) [16]. Technological developments have improved learning in schools. For example, students are using technological tools in learning, such as touch screens, distance learning, and elearning [16]. 
The 3D hologram visualization operates by generating an illusion of 3D imagery. A source of light that is directed onto an object's surface is scattered. Interference between two light sources is developed by the illumination of the object by a second light source. The two sources of the light interface and cause diffraction appearing as a 3D image. Hologram technology has enabled scientists to transfer individuals from one place to the next needless to travel. In the 2008 United States elections, Jessica Yelling was beamed up into the New York Wolf Blitzer studio with a very realistic display [16]. This hologram effect had the highest number of viewers on social media. Figure 1 below shows the Jennifer Yelling Hologram effect.

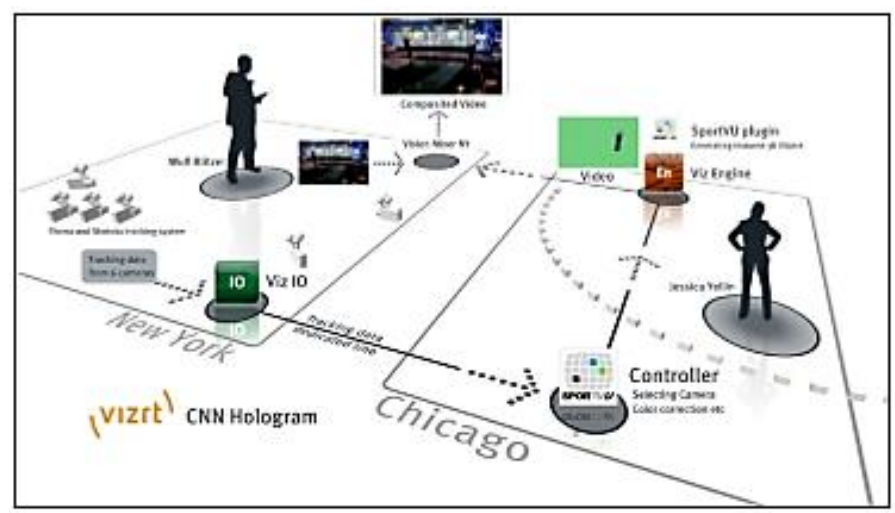

Figure 2: CNN holographic effect of 2008. [11].

Cisco Telepresence system made it possible for Mission System Company to integrate 3D holographic display technology, thus creating the first real-time world visual presentation [16]. Holograms have become part of the society and are no longer considered virtual as the common perception has always been. Life-size 3D Telepresence holograms interact with remote audiences in the world today (politicians, band onstage performance, and CEO's holding meetings around the globe with their colleagues) [31]. Holograms are essential in advertising and marketing, education, and society. Figure 2 below shows the process of hologram creation.

This research paper is devoted to pin-pointing the advantages of holograms in the learning environment and assessing the possible challenges to the implementation of this technology in Egyptian educational theaters, Cairo. 3D holographic technology enables students to be taught with virtual teachers. Virtual images of teachers are projected to a student audience, making learning and instruction dissemination effective [31]. Moreover, famous characters in the field of education can be recast in the classrooms to enhance student understanding. The imagination of great philosophers, such as Plato, appearing as designed virtual images in classes and explaining concepts in philosophy or Sir Albert Einstein explaining his discoveries in the world of sciences can prove to be vital tools in learning [31]. Such tools can profoundly enhance classroom learning by transforming regular teachercentered learning to a more engaging student-centered learning.

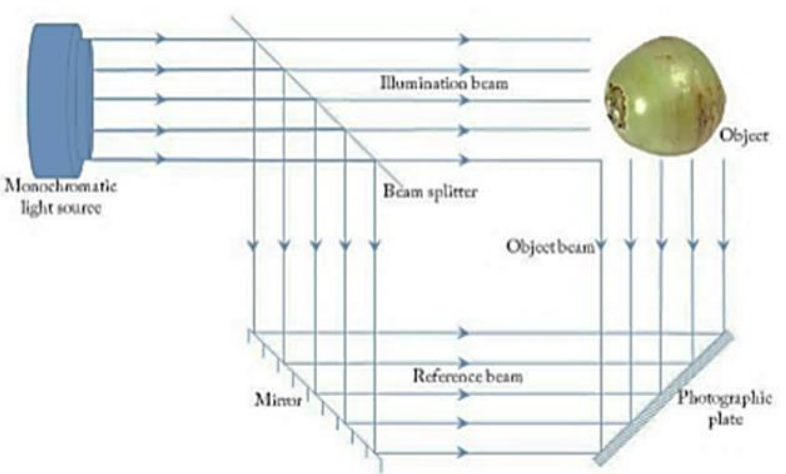

Figure 3: Hologram creation process. [11].

\section{Challenges to Implementing the 3D Holographic Technology} in Learning Institutions

The implementation of 3D holographic technology in the field of education faces myriad challenges. The cost of installing the technology is high, and the personnel handling the equipment needs heightened skills in the field of information technology [16] The internet speed requirement for the 3D holographic technology to take effect is quite high. The technology requires an estimated 20 megabits per second guaranteed constant speed for projection. Scientists are still working to improve the efficiency of holographic projections [33]. The perfect use of the technology requires a screening room with compatible video and lighting technology, which costs approximately $\$ 150,000$ and a display screen accurately for observing holograms at the price of $\$ 215,000$ [33]. The price of implementation and labor costs might add up to $\$$ 500,000 [33].

Embracing holographic technology requires a complete transformation of the architectural design of residential homes. There is a need to create more room to accommodate the delivery and screening technology of the holograms [20]. Educational theaters can be designed to allow for such adjustment to enhance the learning experience of students and foster positive cognitive development in children.

Moreover, Egypt is a country interested in investing in the next generation of technology. 3D holographic imaging is an ideal investment that can facilitate classroom learning [8]. For instance, Artificial Intelligence is fast becoming a world reality. Therefore, holograms installation and cost implications could strike a breakthrough with artificial intelligence. The critical consideration would be installing the technology at present, or giving it time for more advancement, creating a 10-year implementation plan.

Holographic technology is effective in theoretical and practical content delivery in classrooms. Moreover, the technology can be implemented in distance learning, giving students enrolled in such programs an opportunity to study in real classes miles away from their classrooms [16]. The teacherstudent interaction is highly facilitated by 3D holography technology regardless of the barriers of distance and time. In comparison to video-based distance learning in educational institutions, 3D holograms are preferred in distance education. 
However, the cost-effectiveness of the technology has not been exhaustively researched [16].

\section{Educational Theater Design for Hologram Visualization in Egyptian Schools}

The theater design for 3D hologram technology implementation is sleek. The front projection is a conventional design, as shown in Figure 3 below. The theater design follows the front projection principle. Anterior and hindmost screens in the structure of the eyeliner are referred to as bounce screens. The eyeliner receives these plain principles and supplements a special three-layered polymetric foil 25000 of an inch in thickness [34]. The foil is tensioned at an angle of 45 degrees on the screen, as shown in Figure 4 below. The tensioning of the foil facilitates the vertical formation movement of the projector and the bouncing screen.

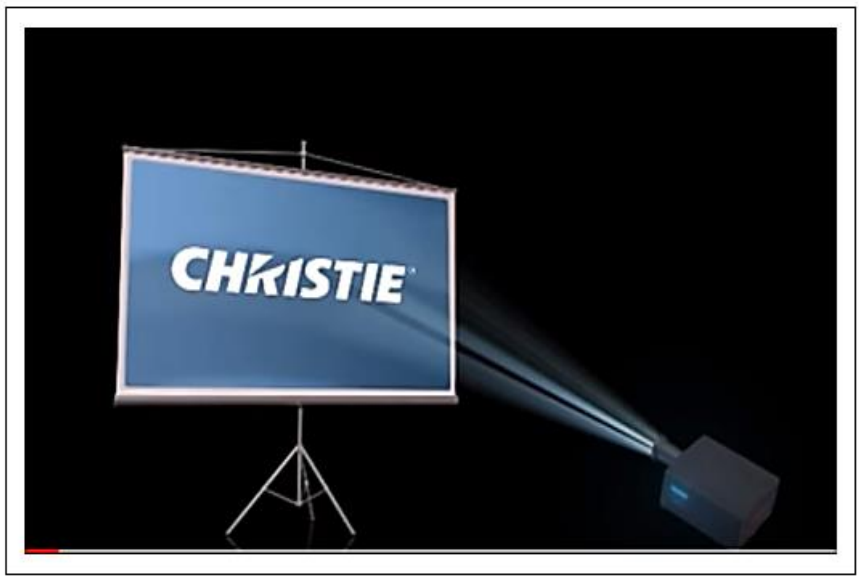

Figure 4: The depiction of front projection [11].

For lesser spaces, designers configure the projectors with mirrors, thereby elongating the projection and enhancing the integrity of the pictures. The displays of the eyeliner need a minimum footprint of 10 square feet and a height of 9 feet to display a whole human.
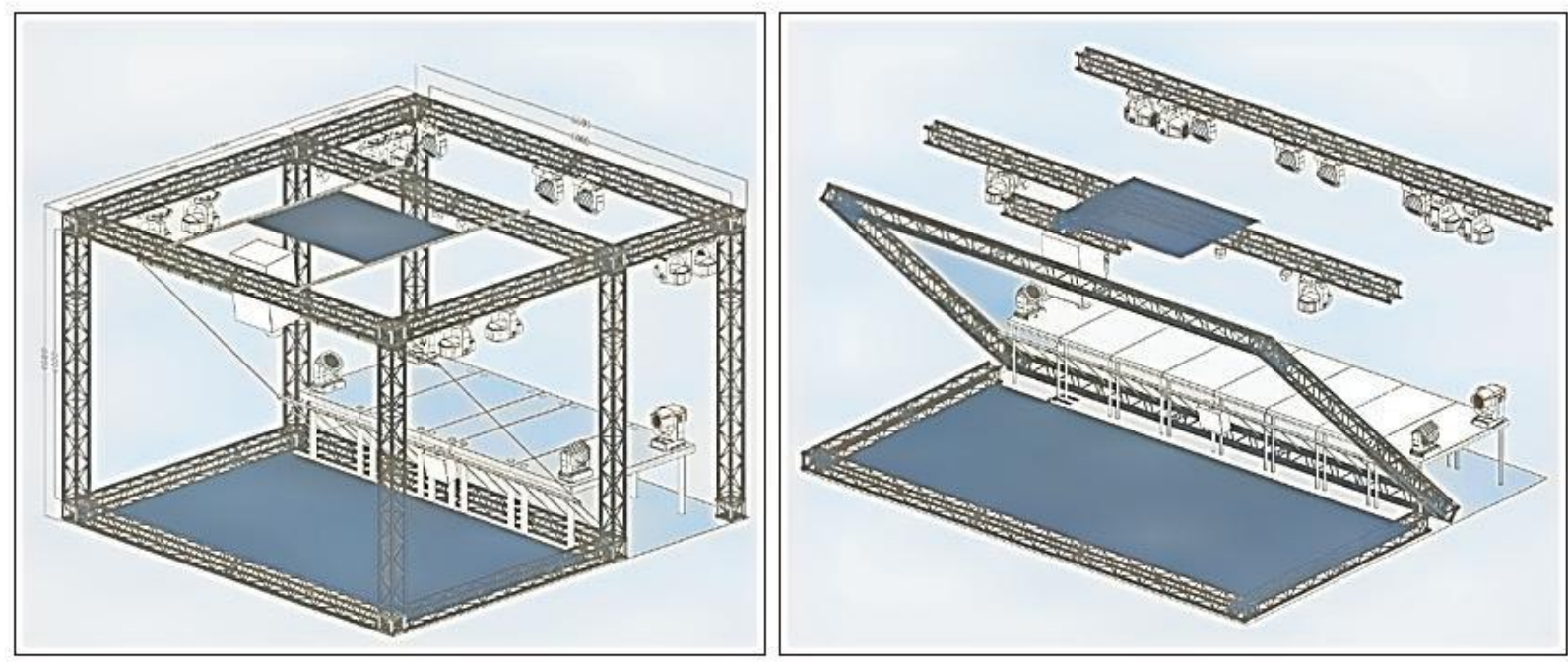

Figure 6: Theater design for the implementation of 3D holographic technology. [11]. 
In the design of the theaters for 3D holographic technology, safety considerations ought to be considered. Safety ought to be part of the design as opposed to an afterthought. The material for the construction of the theater is steel, which is durable and can support the massive equipment installation [16]. Besides, the dais and the theater are wide enough to accommodate the tools needed and the students that occupy the theater.

The researches lack comprehensive research in the inclusion of hologram technology in learning. The substantial equipment costs in the installation of the technology are deemed to reduce as further breakthroughs emerge into the utility of this fundamental technology. Academic institutions (from elementary school to the universities) ought to invest in research and include the technology in the learning of the students specifically, within the school curriculum [16]. Further, before purchasing and investing in the implementation of the technology, learning institutions can get comprehensive information about the technology's cost parameters and installation procedures from companies dealing with installations, such as Virtual-On [35].

\section{CONCLUSION}

The 3D holographic technology succeeded in the invention of laser technology and has currently been used in broad spheres. Scientists project that the 3D holographic technology will be the next generation technology implemented in all aspects of human life; this is a projection, though the technology has proven potential. Currently, 3D holographic technology is used in the film industry for broadcasting 3D films. Besides, politicians and CEOs use technology in their presentations. The ubiquitous use of technology cannot be ignored in the modern technological world. Research is currently ongoing on ways of increasing efficacy and including the technology in daily human experiences.

The importance of holograms as opposed to virtual reality and augmented reality is in the inherent capability to project images in real-time. The images in holography are real-time events; the difference is the location at which the events are broadcasted. Conjuring 3D images has been a frequent impressive occurrence used in advertisements and marketing gimmicks. Products are more appealing when advertised using 3D holographic technology, winning customer appeal. The task of including holographic technology in the learning of children in Egypt is a daunting task. The primary reason being the costbenefit analysis and the implementation requirement of the technology.

The challenges presented by most research respondents with regards to the implementation of the 3D holographic technology in schools are the high costs involved, personnel training, and the effect the technology might have on the learning of the children. Some educators think the technology will have an insignificant impact on the learning of children in schools. It is inaccurate to dismiss the allusions and ideologies set forth by academicians and scientists concerning the technology. The research into the subject is not exhaustive, and the potential of the technology remains unknown.

It is recommended that academic institutions should research the repercussions of hologram technology on the learning of children before doing installations in schools, including in Egypt. Inter-professional collaboration comes in handy in identifying the demerits of the technology in terms of child learning and child psychology. It is reprehensible to ignore the pessimist ideologies regarding the technology. The reliable solution is in conducting research and validating the results based on real experiences.

Possibly, academic institutions ought to adopt long term planning when it comes to the use and implementation of technology. Since the possibilities in the use and application of the 3D holographic technology are futuristic, execution ought to be done in stages in schools. Phase implementation allows research to take effect so that proven and positive effects of the technology can be installed. Further, the costs potentially reduce since the costs involved in testing the efficacy of such technology get diverted to the implementation phase. Possibly Artificial intelligence should take effect and interface with the 3D holographic visualizations before the implementation of the technology in Egyptian schools. Artificial intelligencehologram interfacing might realize the best benefits in academia.

Research has validly forecasted the future of 3D holographic technology. The majority of modern research confirms that the technology will be integrated into several fields. The use of the 3D holography technology in the field of medicine and engineering has been impactful and currently fostering further research to exploit the potential of the technology. Although hologram technology is expensive and not completely known, the technology is a worthy investment, that educators and researchers should integrate into the school curriculum.

Most research focuses on the current use of 3D hologram technology in education, healthcare, and other sectors. However, this research specifically focuses on the current and future use of hologram visualization technology in Egypt's educational theater. There have not been prior studies explicitly dealing with the topic. Therefore, the research findings provide a focus for current and future researchers to explore the potential of 3D holographic technology in Egypt and the world beyond. The research is profoundly relevant because the current $5 \mathrm{G}$ internet coupled with the fast streaming artificial intelligence provides a platform to further develop 3D hologram technology in educational theaters.

\section{RECOMMENDATIONS}

Research has accurately presupposed that 3D holographic projection is bound to be the next generation of effective technology in vast spheres of influence. Research into the efficacy of holograms in educational theater learning is less than a century old. Therefore, no accurate data and cost-benefit analysis have been done regarding the subject. Further, 3D holographic technology in the educational theater is a futuristic technology, and the potential is unknown and unexploited [16]. Researchers are left with simulations and optimization techniques as the primary mechanisms of gauging the efficacy of 3D holographic technology in educational theater in future learning [35]. Academic institutions (before installing 3D holographic technology in educational theaters and including it in their curriculum have to weigh the cost-benefit analysis of 
this technology and the impact it is likely to have on the education theater learning of school children.

Learning intends to increase knowledge and to impact future generations positively. Children are the future generations for which learning intends to shape. Long-term exposure to such a technology could have adverse effects on the cognitive development of children [35]. It is equally possible that technology may make it difficult for children to distinguish between reality and what is considered to be virtual. Therefore, it is essential to comprehend the real influence of hologram technology on child learning [16].

However, it has been understood and proven that visual aids in learning foster expedited learning in school-going children [35]. The effects of information technology on child learning have been unbearable. While the technology facilitates a relaxed and comfortable learning environment, the social media that comes with it has adversely affected children. Social alienation has been at the apex of the demerits, with most children getting stressed over failing to meet the standards set by social media. Modernity and social psychologists, in general, have devised ways of capitalizing on the positive effects and regulating the demerits through including such stringent measures as screen times [8]. Implementation of the 3D holographic technology in educational theaters might bear similar adverse effects, albeit not comprehensively researched; limits ought to be set to minimize the negatives and maximize the positives.

Inter-professional collaboration in the installation of the 3D holographic technology in educational theaters can be instrumental in ascertaining the efficacy of this program in Egyptian school learning. Egypt is a country with vast unexploited potential. The resources in the fast-developing nation can cater for the expenses involved in installing the technology in educational theaters. It is accurate to state that Egypt as a country is ready to include holographic technology in educational theater based on her resource endowment in terms of professionals and expatriates in varied fields. The educational curriculum of the country is equally competitive and produces some of the best professionals in the globe.

Nevertheless, before considering implementing holographic technology in educational theaters in Egyptian schools, it is essential to consider the cost as at now and the future decade projected costs. The reason for such a consideration pegs on the fact that the technology is still in its preliminary stages. Further, 3D holographic technology is bound to advance in the next decade significantly. Therefore, learning institutions can have an open approach to the implementation of technology in educational theaters. The ultimate objective ought to be to ensure cognitive development in the learning of children and facilitate teacher-student classroom interaction. Some scholars mistake the 3D holographic technology in educational theaters to be a replacement for the teacher. 3D holographic technology in educational theaters serves to aid learning and enhance the teacher's work [8].

The primary concern in the design of the educational theater is space, lighting, soundproofing, and decoration. Space should accommodate the total number of students and allow for setting up of equipment. The operators of the theater must control the lighting because excess lighting might interfere with viewing the screens due to the reflection of light. Decorating the theater, showcasing some educational themes to enhance the learning experience of children in the educational theater, is equally important. Lastly, soundproofing will facilitate the projection of quality sound and avoid noise pollution.

\section{Funding and Location Selection}

The use of 3D holographic technology in educational theater in student learning is in its initial phases. Therefore, the technology should be implemented in a location full of professionals and with adequate resources. The resources are fast speed internet access, financial endowment, and equipment availability. Cairo is Egypt's capital with universities and colleges for research. This location is the most convenient for the implementation of the 3D holographic visualization technology.

As earlier discussed, the cost of implementing the technology in educational theaters is high. However, the Egyptian government can provide funding. Moreover, the academic institutions could draft a proposal to the Egyptian government through the ministry of education requesting funding. The proposal should include the equipment costs, labor costs, and the costs of installation. Alternatively, private companies can fund the implementation of technology in educational theaters. These private companies could consist of well-wishers and non-governmental organizations. However, the best option for funding would be from non-governmental organizations supporting education in developed countries in Science, Technology, Engineering, and Mathematics (STEM). Lastly, the respective schools can obtain loans from the government and financial institutions, such as banks, to fund the 3D holographic.

\section{ACKNOWLEDGMENT}

The author gratefully acknowledges the approval and the support of this research study by grant no. (EAR-2019-1-10-F8181) from the Deanship of Scientific Research at Northern Border University, Arar, K.S.A.

\section{REFERENCES}

[ 1] Khooshabeh, P., \& Hegarty, M, "How visual information affects a spatial task", in Proceedings of the Annual Meeting of the Cognitive Science Society, vol.36, no.1, 2020, pp. 2041-2046.

[2] Plantenberg, K, Engineering graphics essentials with AutoCAD® 2014 instruction. Mission, KS: SDC Publications, 2013.

[ 3 ] Khan, J, "Biomedical imaging: 3D digital holograms visualize biomedical applications", Laser Focus World, vol. 49, no. 7, pp. 55-59, 2013. [Accessed on: 3 March 2020].

[ 4 ] Cook, T. J, Architects of catholic culture: designing and building Catholic culture in catholic schools. Washington, DC: National Catholic Educational Association, 2001.

[ 5 ] Winslow, L, Holographic projection technologies of the future: Killer applications. World Think Tank, 2007. 
Available:

http://www.worldthinktank.net/pdfs/holographictechnolo gies.pdf

[ 6 ] Gopalan, C, "The Impact of Rapid Change in Educational Technology on Teaching in Higher Education", HAPS Educator, vol. 20, no. 4, pp. 85-90, 2016. Available: 10.21692/haps.2016.037 [Accessed on: 28 February 2020].

[ 7 ] Lee, H, "3D Holographic Technology and It's Educational Potential", TechTrends, vol. 57, no. 4, pp. 34-39, 2013. Available: 10.1007/s11528-013-0675-8.

[ 8 ] J. Perdomo, M. Shiratuddin, W. Thabet, and A. Ananth, "Interactive 3D Visualization as A Tool for Construction Education", 2005 6th International Conference on Information Technology Based Higher Education and Training, pp. 1-7, 2005. Available: 10.1109/ithet.2005.1560307 [Accessed on: 27 February April 2020].

[9] Orlov, V. V., \& Pavlov, A. V, "On Modeling of the Biological Memory Associative Properties by the Volume Superimposed Holograms Technique", Radiophysics and Quantum Electronics, vol. 57, no. 8-9, pp. 627-634, 2015. Available: $10.1007 / \mathrm{s} 11141-015-9548-7$.

[ 10 ] Hill Jr, R. W., Gratch, J., Marsella, S., Rickel, J., Swartout, W. R., \& Traum, D. R, "Virtual humans in the mission rehearsal exercise system", Künstliche Intelligenz, vol. 4, no. 3, pp. 5-10, 2003. [Accessed on: 8 March 2020].

[ 11 ] Harris, A. L and Rea, A, "Web 2.0 and virtual world technologies: A growing impact on IS education", Journal of Information Systems Education, vol. 20, no. 2, p. 173, 2009. [Accessed on : 8 March 2020].

[12 ] Bove Jr, V. M, "Holographic television", in Optical holography-materials, theory and applications, V. Jr, Ed. Elsevier, 2020, pp. 73-82.

[ 13 ] Németh, B., \& Hoffmann, M, "Gender differences in spatial visualization among engineering students", Annales Mathematicae et Informaticae, vol. 33, no. 1, pp. 169-174, 2006. [Accessed on: 7 March 2020].

[14 ] Strong, S., \& Smith, R, "Spatial visualization: Fundamentals and trends in engineering graphics", Journal of Industrial Technology, vol. 18, no. 1, pp. 1-13, 2001. [Accessed on: 8 March 2020].

[15 ] Ghuloum, H, "3D hologram technology in learning environment", in Proceedings of the informing science \& IT education conference, Informing Science Institute. , 2010, pp. 693-704.

[ 16 ] Bailenson, J. N, N. Yee, J. Blascovich, A. Beall, N. Lundblad, and M. Jin, "The Use of Immersive Virtual Reality in the Learning Sciences: Digital Transformations of Teachers, Students, and Social Context", Journal of the Learning Sciences, vol. 17, no. 1, pp. 102-141, 2008. Available: 10.1080/10508400701793141 [Accessed on: 15 February 2020].

[17] Sudeep, U, "Use of 3D hologram technology in engineering education", Proceedings of the International Conference on Emerging Trends in Engineering (SICETE), vol. 4, no. 1, pp. 62-67, 2013. [Accessed on: 17 February 2020].
[ 18 ] Luévano, E., López de Lara, E., \& Castro, J. E, "Use of Telepresence and Holographic Projection Mobile Device for College Degree Level", Procedia Computer Science, vol. 75, pp. 339-347, 2015. Available: 10.1016/j.procs.2015.12.256.

[19] Kesim, M., \& Ozarslan, Y, "Augmented Reality in Education: Current Technologies and the Potential for Education", Procedia - Social and Behavioral Sciences, vol. 47, pp. 297-302, 2012. Available: 10.1016/j.sbspro.2012.06.654 [Accessed on: 20 February 2020].

[ 20 ] Tosto, M. G., Hanscombe, K. B., Haworth, C. M. A., Davis, O. S. P., Petrill, S. A., Dale, P. S., Kovas, Y, "Why do spatial abilities predict mathematical performance?", Developmental Science, vol. 17, no. 3, pp. 462-470, 2014. Available: $10.1111 /$ desc. 12138 .

[ 21 ] Lee, S., Lee, B., Cho, J., Jang, C., Kim, J., \& Lee, B, "Analysis and Implementation of Hologram Lenses for See-Through Head-Mounted Display", IEEE Photonics Technology Letters, vol. 29, no. 1, pp. 82-85, 2017. Available: 10.1109/lpt.2016.2628906.

[22] Shi, S., \& Morrow, B. V, "E-conferencing for instruction: What works? ", Educause Quarterly, vol. 29, no. 4 2 $2006 . \quad$ Available: https://www.learntechlib.org/p/103804. [Accessed on: 15 March 2020].

[23 ] Toloui, M., \& Hong, J, "High fidelity digital inline holographic method for 3D flow measurements", Optics Express, vol. 23, no. 21, p. 27159, 2015. Available: 10.1364/oe.23.027159.

[ 24 ] L. Rebenitsch and C. Owen, "Review on cybersickness in applications and visual displays", Virtual Reality, vol. 20, no. 2, pp. 101-125, 2016. Available: 10.1007/s10055016-0285-9.

[ 25 ] Khorasaninejad, M., Ambrosio, A., Kanhaiya, P., \& Capasso, F, "Broadband and chiral binary dielectric metaholograms", Science Advances, vol. 2, no. 5, p. e1501258, 2016. Available: 10.1126/sciadv.1501258 [Accessed on: 17 March 2020].

[26 ] Tsutsumi, E, "A Mental Cutting Test using drawings of intersections", Journal for Geometry and Graphics, vol. 8, no. 1, pp. 117-126, 2004. [Accessed on: 27 January 2020].

[ 27 ] Wood, E., Willoughby, T., Reilley, S., Elliott, S., \& DuCharme, M, "Evaluating students' acquisition of factual material when studying independently or with a partner", British Journal of Educational Psychology, vol. 65, no. 2, pp. 237-247, 1995. Available: 10.1111/j.2044-8279. 1995.tb01145. x.

[ 28 ] Baylor, A. L., \& Kim, Y, "Simulating instructional roles through pedagogical agents", International Journal of Artificial Intelligence in Education, vol. 15, no. 1, pp. 95-115, 2005. [Accessed on: 27 January 2020].

[ 29 ] Sheet, A., El Sayed, M., Maged, M., Ismail, M., Ali, M., Solouma, N. H., \& Abdel-Mottleb, T, "3D computergenerated medical holograms using spatial light modulators", Journal of Electrical Systems and Information Technology, vol. 1, no. 2, pp. 103-108, 2014. Available: 10.1016/j.jesit.2014.07.004. 
[ 30 ] Nichols, S., \& Patel, H, "Health and safety implications of virtual reality: a review of empirical evidence", Applied Ergonomics, vol. 33, no. 3, pp. 251271, 2002. Available: 10.1016/s0003-6870(02)00020-0.

[ 31 ] Subrahmanyam, V., \& Ravichandran, K, "Technology online distance mode of learning", International Journal of Humanities and Social Science Invention, vol. 2, no. 1, pp. 5-13, 2013. [Accessed on: 10 February 2020].

[ 32 ] Ahmad, S. A, "Holography in the Nigerian education system: readiness for a redress", in Proceeding of the international conference on humanities sciences and education, Proceeding of the international conference on humanities sciences and education, 2014, pp. 291-310.

[ 33 ] Bobolicu, G, "Live" hologram communication to become reality within five years", 2009. [Online]. Available: http://gadgets.softpedia.com/news/LiveHologram-Communication-to-Become- Reality-within-5Years-1233-01.html. [Accessed on: 09- March - 2020].

[34] Qiu, W., \& Hubble, "The advantages and disadvantages of virtual field trips in geoscience education.", The China Papers, vol. 13, no. 1, pp. 75-79, 2002. [Accessed on: 10 March 2020].

[ 35 ] Rizzo, A., Klimchuk, D., \& Mitura, R, "The virtual classroom: A virtual environment for the assessment of attention processes in children with attention deficit hyperactivity disorder", Anuario de Psicologia, vol. 40, no. 2, pp. 211-222, 2004. [Accessed on: 10 March 2020].

\section{Appendices}

Appendix A

\section{D Holographic Technology in Egypt's Educational Theatre}

- Name: (optional)

- Age: ............. $\square$ Male $\square$ Female

- Governorate:

- The educational administration:

- Job title:

1. Do you know what 3D holographic technology in educational theaters is?
$\square$ Yes
$\square$ No
$\square$ I don't Know

2. Do you think the $3 \mathrm{D}$ holographic technology in educational theaters will enhance learning?
$\square$ Yes
$\square$ No
$\square$ I don't Know

3. Do you think the 3D holographic technology will be a tool for a teacher in educational theaters?
$\square$ Yes
$\square$ No
$\square$ I don't Know

4. Do you think the hologram will be an effective teaching tool in the future in Egyptian educational theaters?
$\square$ Yes
$\square$ No
$\square$ I don't Know

5. What are the possible obstacles 3D hologram visualization in educational theaters might face in terms of incorporation into the learning environment in Egypt?

$\begin{array}{llll}\square \text { High cost of installation } \quad \square \text { Yes } & \square \text { No } \\ \square \text { High internet speeds } \quad \square \text { Yes } & \square \text { No } & \\ \square \text { complicated to use } & \square \text { Yes } & \square \text { No } & \\ \square \text { Student related problems (specify) } & \square \text { Yes } \quad \square \text { No } \\ \square \text { Other(s) obstacles (specify) } & & \end{array}$

6. On a scale of 1 to 10 , how effective do you think 3D holographic technology in Egyptian Educational theaters will facilitate learning?

\begin{tabular}{|l|l|l|l|l|l|l|l|l|l|}
\hline 1 & 2 & 3 & 4 & 5 & 6 & 7 & 8 & 9 & 10 \\
\hline & & & & & & & & & \\
\hline
\end{tabular}

7. Write your perception of the future use of Hologram technology in the school theater:

8. Write your perception of the expected obstacles to using the Hologram technology in the school theater:

\section{Creative Commons Attribution License 4.0 (Attribution 4.0 International, CC BY 4.0)}

This article is published under the terms of the Creative Commons Attribution License 4.0 https://creativecommons.org/licenses/by/4.0/deed.e n_US 